\title{
Economic Challenge of Cardiovascular Disease
}

\author{
Andreia Assis Loures Vale, Anita Saldanha, André Luis Valera Gasparoto, Ana Paula Pantoja, Henrique \\ Andrade Rodrigues da Fonseca and Tania Leme da Rocha Martinez*
}

Nephrology Department, BP - A Beneficência Portuguesa de São Paulo, Brazil

*Corresponding author: Tania Leme da Rocha Martinez, BP - A Beneficência Portuguesa de São Paulo, Brazil.

Published Date: December 02, 2019

\begin{abstract}
Coronary artery disease is the most common cause of death in developed countries worldwide. Reducing, therefore, mortality and morbidity for this condition is one of the most important current challenges of medical practice. An important factor to be discussed as to the benefit of cardiovascular disease prevention is that a high percentage of cases of acute myocardial infarction are unnoticed. Another important data is the progressive "improvement" of living conditions, "aging" our population and thus making it more susceptible to the occurrence not only of coronary disease, but also of brain-vascular events and peripheral arterial pathologies. The complexity of the process involved between the manifestations of coronary artery disease and death allows us to visualize the importance of preventing this pathology and how we can act by reducing costs when we can mitigate the cascade of evolution of coronary artery disease complicators.
\end{abstract}

Keywords: Epidemiology; Cardiovascular disease; Health economics; Coronary disease; Prevention

Abbreviations: AMI: Acute Myocardial Infarction; CAD: Coronary Artery Disease; CVD: Cardiovascular Disease

\section{Introduction}

Coronary artery disease (CAD) is the most common cause of death in developed countries worldwide [1,2,3]. Reducing, therefore, mortality and morbidity for this condition is one of the most important current challenges of medical practice. For this, public health measures are needed developed in a regional way, respecting the peculiarities of the population of each country, region and/or state. This becomes clearer when we recognize that CAD has different risk factors, with a higher predominance of one or the other in the so-called causal models [4].

Aiming at a better understanding of why a given measure has more results than another it is necessary that we know these different models:

1. "classic" model (described as the causal model of CAD in the North American regions and northern Europe): represented by the triad of the main coronary risk factors such as hypercholesterolemia, smoking and arterial hypertension.

2. model of "oxidative stress" (Eastern Europe): developed from food deprivation and therefore with lower cholesterol rates, lower consumption of fruits and vegetables (diet without anti-oxidant elements), associated with the high stress rate of economic origin and alcoholism; presence also of smoking.
3. model of "insulin resistance" (Mediterranean countries, with Luso-Brazilian variant): in these countries the consumption of saturated fats would not exceed that of polyunsaturated; we have as major determinants of hypertension (lusíada variant), obesity (excessive consumption of total fats), alcoholism and also high frequency of non-insulin-dependent diabetes.

It is clear that in a country of continental dimensions like ours, we will have differences in the predominance of one or the other model in the various regions. Another important fact for us to begin our discussion about the benefit of the prevention of cardiovascular disease (CVD) is to remember that a high percentage of acute myocardial infarctions (AMI) are unnoticed, not even being diagnosed; we also know that there is a true entourage of pathologies and/or morbid occurrences resulting from CVD that contribute to the increase in morbidity and mortality of this disease.

\section{Epidemiological Considerations}

In the United States, more than 1 million cases of myocardial infarction occur each year and approximately 7 patients out of 10 survive the acute event. Mortality rates are higher in the first year after infarction and henceforth the risk of death is about 5\% per year for men and $7 \%$ per year for women. After the first infarction, 
the risk of new myocardial infarction is increased by 3 to 6 times and, within 5 years, the risk of any CAD event is up to 80\% [5]. In [6] (Figure 1) we have some data from the Framingham Study on other conditions that increase the risk of patients. Unfortunately, data on the incidence of CAD and its manifestations in Brazil are very scarce. However, data from 1985 (DATAPREV) indicate CVD as the cause of about $80 \%$ of hospitalizations and responsible for $33.3 \%$ of all recorded deaths. Most recent data from the city of São Paulo [7,8,9] - 1993 - give us CVD as a cause of $32 \%$ of all deaths; (Figure 2) shows us proportional mortality by age. We have followed the constant emergence of new techniques and differentiated approaches to heart diseases, which makes us think how we still continue with this high mortality rate. The MONICA [10] Project clearly showed that the incidence of coronary heart disease is a more important determinant than the medical care provided; the decrease in sudden death was much higher than that of AMI diagnosed and installed, suggesting that the incidence changed more than lethality. Another important data is the progressive "improvement" of living conditions, "aging" our population and thus making it more susceptible to the occurrence not only of coronary disease, but also of brain-vascular events and peripheral arterial pathologies [11]. The complexity of the process involved between the manifestations of CAD and death allows us to visualize the importance of preventing this pathology and how we can act by reducing costs when we can mitigate the cascade of evolution of CAD complicators.

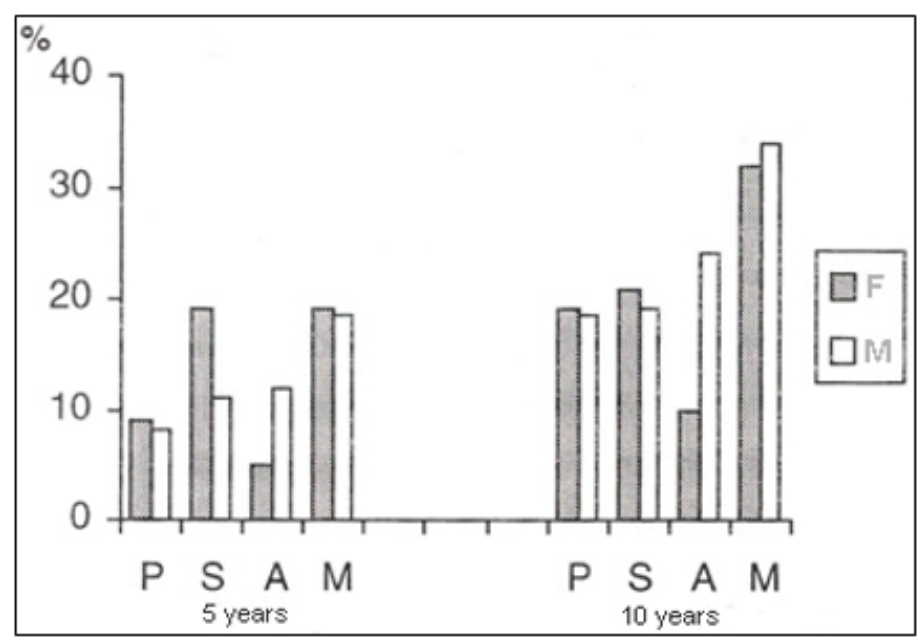

$\mathrm{A}=$ angina, $\mathrm{M}=$ myocardial infarction, $\mathrm{P}=$ peripheral arterial disease, $\mathrm{S}=$ stroke.

Figure 1: Risk of death from coronary artery disease after 5 and 10 years of the first event for men and women who suffered the following cardiovascular conditions [6].

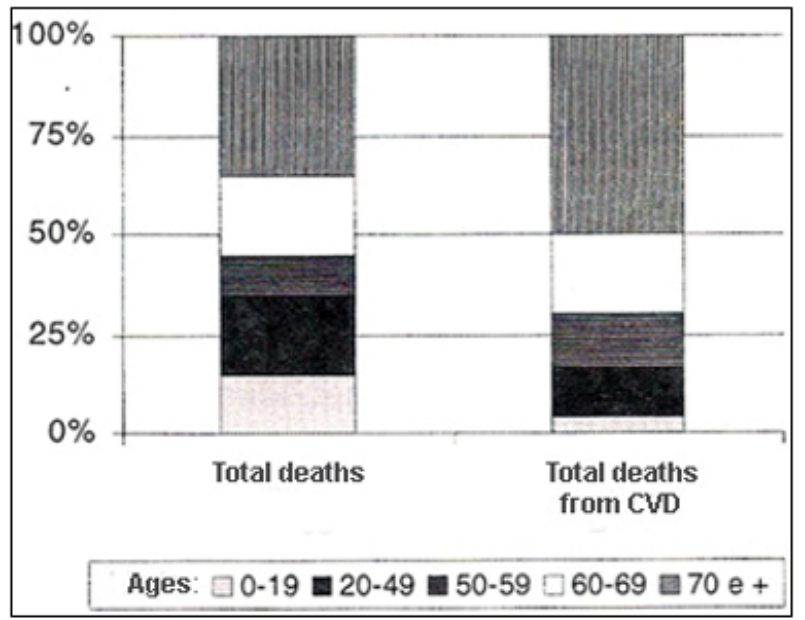

Figure 2: Proportional mortality by age in São Paulo, 1993 [7]: Total deaths and deaths from cardiovascular disease.

\section{Cost-benefit Approach in the Prevention of CAD}

Numerous methods have been used in cost-benefit analysis, from the economic evaluation of the intervention in CAD to the benefit from the return of patients to their work functions, through analysis techniques that involve knowledge of the annual cost of treatment in question per patient [12,13,14]. For example, the estimate of cost per year and extended living - the cost per year of life gained or saved - has been an important indicator of the benefit of treatment that leads to increased life expectancy $[15,16]$. In this case, pharmacological therapy is efficient and effective 
in secondary prevention, with favorable cost-benefit ratio; in primary prevention, this relationship would be favorable only in those high-risk subgroups $[17,18]$. Another method used is that based on the incorporation of patient participation in the choice of therapeutic decision that would most apply to their pathology - "cost per quality-adjusted year of life" [19]. In this case, what was verified was a satisfactory economic justification, where the patient himself attributes values to the possible years gained from the treatment. The Newcastle Centre for Clinical Epidemiology and Biostatistics Group (Australia) [20] compared the cost-benefit of lowering cholesterol levels in the prevention of CAD comparing the population of a given region and two specific risk groups for CAD in the same population: men between 35 and 64 years who presented high risk or borderline risk to high. The intervention strategy was the dietary orientation for hypercholesterolemia. Analyzing the cost of deployment and the number of reduced events, the following cost reductions were observed, in U.S. dollars, by avoided event: in the high-risk group, savings of $\$ 482,224$; in the medium to high risk group, savings of $\$ 369,098$ and in the population, generally saving $\$ 46,667$. Of course, these are already very satisfactory figures. Regarding the technique that uses the patient's return to work, a study conducted to evaluate post-AMI cardiac rehabilitation compared American and German results, evidencing the superiority of the U.S. program, where 8 weeks of treatment 4 to 6 in Germany [21]. The largest investment in rehabilitation in the U.S. allowed the return to work of about $80 \%$ of patients after 6 months of treatment while among German patients the return to work was less than $50 \%$. Unfortunately, we do not have such concrete numerical data in Brazil, but it is not difficult for us to imagine how far we are even from a prevention policy. If there are already numerous government difficulties in the USA to implement these measures disclosed, in Brazil there is still not even a body that is dedicated to implementing this type of measure [22].

According to lunes [23] these techniques would be inadequate for preventive programs that were linked to the patient's behavior change, since it would depend on the individual capacity of each to modify their lifestyle. These examples mentioned above show us that, although the investment in prevention is expensive, its result brings benefits not only from an economic point of view but also from the point of view that matters most: the reduction of mortality and/or morbidity of this disease so present in our days.

\section{Action On Risk Factors}

In order to develop the best treatment strategy of a patient, it is necessary that we trace their risk profile, differentiating the risk indicator from the risk factor for CAD. For example: man at the age of 50 years for patients with dyslipidemia, that is, age as an indicator and dyslipidemia as a proven risk factor both in the triggering of the disease and in the worsening of a pre-existing one. Based on the analysis of the presence of so-called classic risk factors (see picture) and the presence or not of prior CAD (primary or secondary prevention) is that we can better define the costbenefit ratio of treatment [24] (Table 1). Although there are few studies that analyzed the intervention in risk factors - change in lifestyle [25] - we know, of course, that this intervention is justified in those so-called high-risk patients, without presenting a worse cost-benefit ratio of the that drug treatment.

Table 1: Modification of Cardiovascular Risk Factors [24].

\begin{tabular}{|c|}
\hline Non-Modifiable: \\
\hline Age \\
\hline Sex (dependent age) \\
\hline Family history (+) for coronary artery disease \\
\hline Modifiable: \\
\hline H.A.S. \\
\hline Smoking \\
\hline Diabetes \\
\hline Sedentary Lifestyle \\
\hline Overweight/Obesity \\
\hline Stress \\
\hline Dyslipidemia (LDL-c) \\
\hline Partially Modifiable: \\
\hline HDL-c low \\
\hline Lp(a) increased \\
\hline Fibrinogen increased \\
\hline
\end{tabular}

To demonstrate this, Kupersmith and collaborators [26] conducted a joint survey of some studies on risk factors:

\section{Preventive therapy in lipid reduction (8 studies)}

Evidenced was favorable in secondary and primary prevention in spite of being highly costly but justifiable when other risk factors were coexisted;

\section{Hypertension (5 studies)}

It is always favorable, regardless of the antihypertensive drug used, especially if there is more than one associated risk factor;

\section{Cessation of smoking habit (4 studies)}

Difficult to evaluate, but there was a high beneficial relationship;

\section{Physical exercise (1 study): favorable.}

Among all the risk factors mentioned above (Chart 1), dyslipidemia is the one that presents the most studies clearly demonstrating the economic and social benefit of measures implemented for its correction $[27,28]$. The fact that primary prevention has been considered costly should be better elucidated: we know that it is effective (study already published - WOSCOPS) and that it also presents favorable economic results [29,30,31].

\section{Conclusion}

Nowadays it makes no sense to refer to a given therapeutic process without knowing, properly, its annual cost per patient, its degree of efficacy and its cost-benefit ratio. Our interest, as health professionals, should always be to influence the adoption of preventive measures, whether at the individual or population level, knowing all these conditions well. We cannot forget that the cost 
of treatment of coronary patients involves all procedures inherent to the disease such as: hospital admissions, cardiac catheterization, angioplasty, myocardial revascularization surgery, rehabilitation heart, among others, remembering the impairment caused by the removal of these patients, usually at the height of their productive phase, from work. When we talk about economic challenge, we should always keep in mind that this is related to health promotion, improving the quality of life of our patient. And it is our duty to make this cost-benefit ratio always favorable, seeking the correct stratification of risk of the patient and limiting our drug and/or diagnostic interventions when really necessary.

\section{Acknowledgments}

None.

\section{Conflicts of Interest}

No conflict of interest.

\section{References}

1. Kannel WB, Cupples LA, D'Agostino RB (1987) Sudden death risk in overt coronary heart disease: the Framingham Study. Am Heart J 113(3): 799-804.

2. Kannel WB, Sorlie P, McNamara PM (1979) Prognosis after initial myocardial infarction: the Framingham Study. Am J Cardiol 44(1): 53-59.

3. Kannel WB, Abott RD (1984) Incidence and prognosis of unrecognised infarction: an update on the Framingham Study. N England J Med 311(18): 1144-1147.

4. Lotufo P (1995) Comunicação feita na Jornada Científica do INCOR sobre Insuficiência Coronariana.

5. Watts GF, Lewis B, Brunt JN, Lewis ES, Coltart DJ, et al (1992) Effects on coronary artery disease of lipid-lowering diet, or diet plus cholestyramine, in the St Thomas Atherosclerosis Regression Study (STARS). Lancet 339(8793): 563-569.

6. Kannel WB, Wolf PA, Carrison RJ (1988) The Framingham Study, Section 35: Survival Following Initial Cardiovascular Events. National Hear Lung and Blood Institute Bethesda.

7. Ramos LR, Santos FRG, Marcopito LF (1996) Morbidade e mortalidade por doenças cardíacas em São Paulo. In: SOCESP - Cardiologia. São Paulo: Atheneu.

8. Ramos LR, Saad PM (1990) Morbidade da População Idosa. In: Fundação SEADE. 0 idoso na Grande São Paulo. São Paulo: Seade eds. (Coleção Realidade Paulista)

9. DATASUS (1995) Gerência Técnica de Disseminação de Informações (GTDI). Sistema de Informações Hospitalares do Sistema Único de Saúde (SIH/SUS). Ministério da Saúde, Fundação Nacional de Saúde. Datasus Rio de Janeiro.

10. FINMONICA (1986) Monitoring of Trends and Determinants of Cardiovascular Disease in Finland (Party of a Joint Study) - The MONICA Project. Helsinki: National Public Health Institute.

11. Dzau V, Braunwald E (1991) Resolved and unresolved issues in the prevention and treatment of coronary artery disease: a workshop consensus statement. Am Heart J 121(4): 1244-1263.

12. Drummond MF, Heyse J, Cook J, Alistair McGuire (1993) Selection of end points in economic evaluations of coronary-heart disease interventions. Med Decis Making. 13(3): 184-190.
13. Bays HE, Dujovne CA (1992) Drug therapy for hyperlipidemia. When reducing cadiovascular risk is a priority. Postgrad Med 91(5): 162-193.

14. Roquebrune JP, L'Héritier P, Gibelin P, Baudouy M, Camous JP, et al. (1992) How to evaluate the cost/effectiveness ratio of different therapies of coronary disease. Arch Mal Couer Vaiss 85(2): 239-244.

15. Plans Rublo P, Rovira Forns J (1995) Cost effectiveness of pharmacologic treatments for the reduction of blood lipids. Med Clin (Barc) 105(9): 327-333.

16. Hux JE, Levinton CM, Naylor CD (1994) Prescribing propensity: influence of life-expectancy gains and drug costs. J Gen Intern Med 9(4): 195-201.

17. Schulman KA, Kinosian B, Jacobson TA, Glick H, Willian MK, et al. (1990) Reducing high blood cholesterol level with drugs. Cost-effectiveness of pharmacologic management. JAMA 264(23): 3025-3033.

18. McBride PE, Davis JE (1992) Cholesterol and cost-effectiveness. Implications for practice, policy and research. Circulation 85(5): 1939 1941.

19. Nease RF Jr, Owens DK (1994) A method for estimating the costeffectiveness of incorporating patient preferences into practice guidelines. Med Decis Making 14(4): 382-392.

20. Kinlay S, O'Connell O, Evans D, Judith Halliday (1994) The costeffectiveness of different blood-cholesterol-lowering strategies in the prevention of coronary heart disease. Aust J Public Health 18(1): 105110.

21. Kubler W, Niebauer J, Kreuzer J (1994) Cost/benefit relations: evaluation of inpatient and ambulatory rehabilitation. Z Kardiol 83(Suppl 6): 151158.

22. Wyman M, Feeley J, Brimacombe G, K Doucette (1995) Core and comprehensive health care services: 4. Economic issues. CMAJ 152(10): 1601-1604

23. Iunes RF (1991) On the economic analysis of response to preventive measures. Rev Saúde Pública 25(4): 243-250.

24. Castelli WP, Wilson PWF, Levy O (1990) Serum lipids and risk of coronary artery disease. In: Leaf A, Weber PC, eds. Prevention and Noninvasive Therapy of Atherosclerosis. New York: Raven Press p.7-19.

25. Millar JA (1995) Economic comparison of drug and lifestyle treatment of cardiovascular risk factors in high-risk patients. Clin Exp Pharmacol Physiol 22(3): 217-219.

26. Kupersmith J, Holmes-Rovner M, Hogan A, David Rovner, Joseph Gardiner, et al. (1995) Cost-effectiveness analysis in heart disease, part II: Preventive therapies. Prog Cardiovasc Dis 37(4): 243-271.

27. Glick H, Heyse JF, Thompson D, Robert S Epstein (1992) A model for evaluating the cost-effectiveness of cholesterol-lowering treatment. Int ] Technol Assess Health Care 8(4): 719-734

28. Goldman L, Gordon DJ, Rifkind BM, SB Hulley, AS Detsky, et al. (1992) Cost and health implications of cholesterol lowering. Circulation 85(5): 1960-1968.

29. Sacks F, Pfeffer MA, Braunwald E (1995) A Symposium: Cholesterollowering trials: new results and emerging issues. Am J Cardiol 76(9 Suppl 1): 1C-126C.

30. Gaspoz JM, Kennedy JW, Orav EJ, Lee Goldman (1996) Cost-effectiveness of prescription recommendations for cholesterol-lowering drugs: a survey of a representative sample of American cardiologists. J Am CoII Cardiol 27(5): 1232-1237.

31. Martens LL, Guibert R (1994) Cost-effectiveness analysis of lipidmodifying therapy in Canada: comparison of HMG-CoA reductase inhibitors in the primary prevention of coronary heart disease. Clin Ther 16(6): 1052-1062. 